Portland State University

PDXScholar

\title{
Are the Goals of Sustainability Interconnected? A Sociological Analysis of the Three E's of Sustainable Development Using Cross-Lagged Models with Reciprocal Effects
}

Matthew Thomas Clement

Texas State University

Nathan Pino

Texas State University

Patrick Greiner

Vanderbilt University

Julius A. McGee

Portland State University, cjulius@pdx.edu

Follow this and additional works at: https://pdxscholar.library.pdx.edu/soc_fac

Part of the Income Distribution Commons, Inequality and Stratification Commons, and the Work, Economy and Organizations Commons

Let us know how access to this document benefits you.

\section{Citation Details}

Clement, M. T., Pino, N., Greiner, P., \& McGee, J. (2020). Are the Goals of Sustainability Interconnected? A Sociological Analysis of the Three E's of Sustainable Development Using Cross-Lagged Models with Reciprocal Effects. Sociology of Development, 6(1), 91-115.

This Article is brought to you for free and open access. It has been accepted for inclusion in Sociology Faculty Publications and Presentations by an authorized administrator of PDXScholar. Please contact us if we can make this document more accessible: pdxscholar@pdx.edu. 


\title{
Are the Goals of Sustainability Interconnected? A Sociological Analysis of the Three E's of Sustainable Development Using Cross-Lagged Models with Reciprocal Effects
}

\begin{abstract}
Conceptual discussions of sustainability emphasize the interdependent relationship between relevant social and environmental factors. Yet, traditional quantitative analyses of the topic have tended to estimate the exogenous or direct/indirect effects a predictor variable has on a particular measure of sustainability. We examine the endogenous, interdependent relationship between the three $E^{\prime} s$ of sustainability (economy, equity, and ecology), incorporating country-level data for 1990 through 2015 into cross-lagged structural equation models with reciprocal and fixed effects. Results from these longitudinal models suggest that over time, at the country level, increasing economic inequality reduces renewable energy consumption, with no evidence of reciprocal feedback. Keeping in mind the limitations of the analysis, we tentatively argue that the modern form of development has constrained the potential for the sustainability goals to feed back into each other. KEYWORDS sustainability, modernization, inequality, structural equation modeling, reciprocal effects
\end{abstract}

\section{INTRODUCTION}

From a variety of disciplines, social scientists have studied the topic of sustainability, contributing to the question of how global society can reduce its impact on the planet. In the quantitative literature on the topic, there is an abundance of research exploring the effects of different predictors on a variety of sustainability outcomes. A significant portion of this research has used regression analysis to examine the exogenous effects of social forces on a dependent variable (e.g., Jorgenson and Clark 2012; Rosa et al. 2015; Thombs 2017, 2018; York and McGee 2017). Other quantitative scholars have taken advantage of structural equation modeling to tease out the direct and indirect effects of predictor variables on a measure of sustainable development (e.g., Austin and McKinney 2016; Burns et al. 1994; Jorgenson 2003; Kick and McKinney 2014; Kick, McKinney, and Thompson 2011).

Meanwhile, academic discussion of sustainability, especially in terms of the three E's of economy, equity, and ecology (e.g., Passerini 1998), is often not framed in unidirectional terms, with a predictor variable having an independent effect on a particular outcome. ${ }^{\mathrm{I}}$ Rather than this input-output model, the conceptual discussion of the three E's of

Sociology of Development, Vol. 6, Number I, pps. 9I-II5. electronic ISSN 2374-538X. (c) 2020 by the Regents of the University of California. All rights reserved. Please direct all requests for permission to photocopy or reproduce article content through the University of California Press's Reprints and Permissions web page, https://www.ucpress.edu/ journals/reprints-permissions. DOI: https://doi.org/I0.1525/sod.2020.6.I.9I. 
sustainability has presumed that the relevant social and environmental factors are interdependent (e.g., Edwards 2005), engaged in feedback loops in which there are reciprocal effects between the different dimensions of sustainability. Modernization theory has influenced this approach to sustainability (Huber 2000), which, as we discuss below, became a conceptual guide for the UN's Sustainable Development Goals (SDGs). As the UN acknowledges, the goals "are part of an ambitious, bold sustainable development agenda that will focus on the three interconnected elements of sustainable development: economic growth, social inclusion and environmental protection" (United Nations Information Service 2015). In other words, the three E's of sustainability, according to this framework, are interdependent, such that progress toward one dimension of sustainability reciprocally fosters progress toward another.

In this project, we empirically investigate this claim of interconnection between the goals of sustainability. It is important to test this claim as it not only constitutes the basic argument about the three E's but also underpins the discourse on government policies meant to meet the SDGs. We ask whether there is an interdependent, reciprocal relationship between the different goals of sustainable development, focusing on the three E's of sustainability: ecology, equity, and economy. At the country level, as operational measures of the three E's, we collect information on three variables: renewable energy consumption (as a percentage of total energy consumption), the Gini coefficient, and GDP per capita, all observed in the years 1990 through 2015 . We then incorporate these variables into longitudinal structural equation models (SEMs), relying on methodological developments in SEM ${ }^{2}$ to test reciprocal relationships (Allison, Williams, and Moral-Benito 2017; Bollen and Brand 2010; Paxton, Hipp, and Marquart-Pyatt 20II; Selig and Little 2012). Specifically, we employ reciprocal, cross-lagged models with fixed effects. This robust analytic technique estimates the cross-lagged effects for any two-variable combination while controlling for temporal autocorrelation within each variable.

While autoregressive models yield conservative coefficients, given that they control for temporal autocorrelation, a longitudinal SEM with cross-lagged effects has limitations, mostly due to sample size, which we discuss in detail in Appendix A. Here, we acknowledge these limitations up front while underscoring that this project helps lay the analytical groundwork for future socio-ecological research on whether there are reciprocal relationships between the different dimensions of sustainability. While it makes sense to examine country-level data, given the UN's focus on sustainable development, a quantitative analysis of the interconnection between the three E's would also be applicable to lower levels of analysis (counties, cities, individuals, etc.).

On that note, for the sake of showcasing SEM as a tool to examine reciprocal effects, we present our analysis as a test of an existing framework. Our explicit aim is to evaluate, per the modernization discourse on sustainability (which has been incorporated by the UN into the SDGs), whether the three E's of sustainability are reciprocally interconnected. ${ }^{3}$ To that end, in the following sections of the paper, we first draw on the UN discourse to lay out the conceptual framework for the analysis. While the UN explicitly highlights the interdependent relationship between the SDGs, the details of these interconnections are not fully articulated. Therefore, to derive hypotheses, we also engage environmental sociology and the 
modernization framework that influenced the creation of the SDGs. Next, we review the data and methods we use to estimate the reciprocal effects between the three E's of sustainability (renewable energy consumption, the Gini coefficient, and GDP per capita), all measured at the country level between 1990 and 2015 .

In summary, we find evidence that one direction of a two-variable reciprocal relationship is significant: specifically, greater equality results in more renewable energy consumption, a finding consistent with previous research (e.g., Knight, Schor, and Jorgenson 2017). While we acknowledge that a cross-lagged model ensures conservative estimates, the inherently small sample size at the country level also constrains the complexity of the model, as we detail in Appendix A. Thus, while we conduct hypothesis testing, we emphasize this project as a template for future sociological scholarship to investigate whether measures of sustainability are reciprocally related at lower levels of analysis, with bigger sample sizes. With this qualification, in the conclusion, we discuss the theoretical and policy implications of these findings, with a focus on how national governments meet the goals of sustainable development.

\section{LITERATURE REVIEW}

The UN General Assembly adopted the 2030 Agenda for Sustainable Development (General Assembly 70/I) in September 2015. The agenda contains 17 SDGs (Table I),

TABLE 1. The United Nations Sustainable Development Goals (2015)

1 End poverty in all its forms everywhere

2 End hunger, achieve food security and improved nutrition and promote sustainable agriculture

3 Ensure healthy lives and promote well-being for all at all ages

4 Ensure inclusive and equitable quality education and promote lifelong learning opportunities for all

$5 \quad$ Achieve gender equality and empower all women and girls

6 Ensure availability and sustainable management of water and sanitation for all

$7 \quad$ Ensure access to affordable, reliable, sustainable and modern energy for all

8 Promote sustained, inclusive and sustainable economic growth, full and productive employment and decent work for all

9 Build resilient infrastructure, promote inclusive and sustainable industrialization and foster innovation

10 Reduce inequality within and among countries

11 Make cities and human settlements inclusive, safe, resilient and sustainable

12 Ensure sustainable consumption and production patterns

13 Take urgent action to combat climate change and its impacts

14 Conserve and sustainably use the oceans, seas and marine resources for sustainable development

15 Protect, restore and promote sustainable use of terrestrial ecosystems, sustainably manage forests, combat desertification, and halt and reverse land degradation and halt biodiversity loss

16 Promote peaceful and inclusive societies for sustainable development, provide access to justice for all and build effective, accountable and inclusive institutions at all levels

17 Strengthen the means of implementation and revitalize the global partnership for sustainable development 
encompassing 169 targets, meant to provide a universal framework for achieving environmental sustainability and realizing human rights across multiple issue areas. If all the targets listed under a goal are reached, then presumably the goal itself has been achieved. The SDGs were preceded by the Millennium Development Goals (MDGs), which were adopted in 2000 (General Assembly 55/2). The eight MDGs were meant to explicitly place human development at the center of the global development agenda, and to create a framework of accountability composed of time limits and measurable outcomes for the international community to follow (Fukuda-Parr 2004).

In the lead-up to the formalization of the SDGs, as quoted above in the introduction, the United Nations Information Service explained that the SDG framework is premised on the claim that the three E's of sustainability are interconnected, explicitly recognizing the reciprocal relationship between these goals. The SDGs, according to the United Nations Development Programme (2019), "are interconnected-often the key to success on one will involve tackling issues more commonly associated with another." The language of interdependence continues to be used into the present, as seen in the UN's High-Level Political Forum on Sustainable Development in $2018 .{ }^{4}$ At the meeting, the president of the UN's Economic and Social Council, which presides over the forum, emphasized the "indivisible, integrated and interlinked nature of the SDGs and of the three dimensions of sustainable development" (UN Economic and Social Council 2018). The notion of interconnection is evident not just in the UN but in other organizations with interests that overlap with the SDGs. For instance, highlighting the public health implications of the SDGs, the World Health Organization (2015) writes that the relationship between the dimensions of sustainability is "dynamic and reciprocal." In this sense, the discourse on sustainability, as embraced by the international development community, emphasizes the interdependent, reciprocal relationship between the goals of sustainable development.

Before proceeding, we make two points of clarification regarding the practical focus of this discourse as well as the language of interconnection in the sustainability literature. First, when the UN and sustainability scholars discuss the interconnections of the SDGs, they are often not making a historical statement about observed past relationships between operational measures representing the three E's of sustainability; rather, they are referring to the design of policy to move countries toward these objectives in the future (e.g., Le Blanc 20r5; McCollum et al. 2018; Tosun and Leininger 2017). In a thorough joint scientific review of the SDGs, the International Council for Science and the International Social Science Council (2015) discuss in detail, for policy purposes, the potential links between the broader goals and specific targets of sustainable development. The joint report mentions, for instance, that policies to facilitate access to modern, renewable energy should help lay the foundations for sustainable agriculture and food security, which raises educational levels, promoting economic growth and reciprocally facilitating access to modern, renewable energy. While we recognize the complexity of this example, we mention it here simply to emphasize that many scholars are thinking about reciprocity in terms of the design of future policy to achieve the SDGs. ${ }^{5}$ Our immediate interest here, however, is not the potential for reciprocity in future policy design but whether past dynamics reflect an interdependent relationship between variables representing the three E's of sustainability. 
Second, the use of the term "interconnection" (or "interdependence," "interlinked," etc.) may elicit a variety of analytic techniques used to assess associations between social and environmental variables. For instance, outside sociology, some researchers have used network analysis to explore interlinkages between socio-environmental variables (e.g., Le Blanc 2015). Within sociology, quantitative scholars may assess interconnections through statistical processes of moderation, for example multiple variable interaction (e.g., Thombs 2017; York and McGee 2017), or mediation, that is, the indirect effect of a predictor through an intermediary variable (e.g., Austin and McKinney 2016; Jorgenson 2003). Meanwhile, in the present analysis, we employ an alternative understanding of interconnection. Given the discourse on sustainability, which derived from modernization theory, as we elaborate on below, we use "interconnection" to refer to reciprocal, interdependent relationships between endogenous variables. To that end, we turn to SEM (e.g., Allison, Williams, and MoralBenito 2017), using cross-lagged models to examine whether over time there are reciprocal effects between the different dimensions of sustainability, that is, whether changing the value of one variable reciprocally changes the value of another. Cross-lagged models (which include bidirectional tests) are tools that sustainability scholars outside sociology have been using (Apergis and Payne 2010; Lund and Cois 2018; Richter, Thøgersen, and Klöckner 2017). In our analysis, we will focus on the reciprocal relationship between the three E's of sustainability: ecology, equity, and economy. The variables we use in the analysis to represent the three E's are renewable energy, Gini coefficient, and GDP per capita. These measures are most directly related to targets associated with SDGs 7 (affordable and clean energy), 8 (decent work and economic growth), and io (lower inequality).

Despite the attention to the interdependence of the SDGs, especially by the International Council for Science and the International Social Science Council (2015), the discourse of the development community does not fully articulate the details of these interconnections. Therefore, we turn to the environmental sociological literature, engaging theories of development, notably modernization, which influenced the creation of the SDGs (and the MDGs that preceded them). For clarification, we are not immediately interested in the ongoing debate on the environmental implications of modernization theory (e.g., Foster 2012). Rather, we recognize the role modernization theory has played in the sustainability literature (e.g., Huber 2000); by evaluating this framework we demonstrate the utility of a reciprocal effects analysis for future environmental research in sociology. In the conclusion, we will assess this framework in light of the results and caveats of the analysis.

\section{Socio-ecological Interconnections}

For decades now, environmental social scientists have highlighted the interconnected relationship between society and the environment (Catton and Dunlap 1978; Longo et al. 2016). "In fact," wrote Catton and Dunlap (1978:44), in one of the foundational calls for the formation of an environmental sociology subdiscipline, "the study of the interaction between the environment and society is the core of environmental sociology" (italics in the original). In other words, sociologists studying environmental dynamics should not simply be asking questions about unidirectional relationships-looking at either the effect of environment on society or the effect of society on the environment-rather, environmental 
sociology should also consider the interdependence of humans and the environment, akin to what Schnaiberg (1975) called the "societal-environmental dialectic." For practical research purposes, we interpret this dialectic in the most general sense, as an interdependent dynamic between human and ecological variables such that changing one variable in this dynamic reciprocally changes the other, ultimately in either a positive or negative feedback loop, that is, a reciprocal process of "amplification" or "control," respectively (Paxton, Hipp, and Marquart-Pyatt 2011).

All the same, in the decades since Catton and Dunlap's original call, the major contributions by quantitative scholars in the subdiscipline have come primarily from the analysis of exogenous effects (e.g., Jorgenson and Clark 2012; Rosa et al. 2015; Thombs 2017, 2018; York and McGee 2017) and from the use of SEMs looking at direct/indirect effects (e.g., Austin and McKinney 2016; Burns et al. 1994; Jorgenson 2003; Kick and McKinney 2014; Kick, McKinney, and Thompson 20II). Only rarely have quantitative sociologists engaged methods to test this reciprocal relationship (e.g., Elliott and Clement 2017). ${ }^{6}$ Clearly, two important reasons for this have to do with the ready availability of cross-sectional panel data (Liu et al. 2007), as well as the relevant statistical tools (Allison, Williams, and Moral-Benito 2017; Bollen and Brand 2010; Paxton, Hipp, and Marquart-Pyatt 20II; Selig and Little 2012), which have only recently been implemented in commonly used statistical software packages. Again, we will discuss these methods below; here, we simply make the point that the longitudinal data and methods are now readily available, allowing quantitative scholars to examine the reciprocal relationship between social and ecological variables over time (e.g., Apergis and Payne 2010; Lund and Cois 2018; Richter, Thøgersen, and Klöckner 2017).

While the UN discourse on sustainability provides the language of interconnection, it does not offer specific propositions or hypotheses to test. Given this, we turn to a discussion of the theoretical frameworks which influenced the creation of the SDGs and contribute testable propositions about the interconnections of the three E's of sustainability.

\section{Modernization and the Three E's}

The SDGs, and the MDGs that preceded them, are influenced by a combination of theoretical approaches to development, namely modernization theory but also neoliberalism and the capability approach (Blaustein et al. 2018; Fukuda-Parr 2004; Weber 2014). The capability approach, originally developed by Amartya Sen (1973, 1999, 2011), contended that the enjoyment of individual freedoms and social justice are maximized only if poverty is eliminated and inequalities are reduced. Socioeconomic development is seen as a means to an end and requires local empowerment and participation in addressing development issues in a flexible manner (Fukuda-Parr 2003; Robeyns 2005). Economic growth is therefore desirable only if it improves people's quality of life and removes any "obstacles in their lives so that they have more freedom to live the kind of life that, upon reflection, they have reason to value" (Robeyns 2005:94). Sen's ideas were highly influential at the UN and among other development actors: they were incorporated into the first Human Development Report (United Nations Development Programme 1990), which argued that government budgets 
and policies should balance economic and social spending. The capability approach was also evident in the MDGs, which prioritized human development and poverty in the global development agenda (Fukuda-Parr 2004), and the SDGs, at least five of which explicitly address human development issues (Table $\mathrm{I}$ ).

The sustainable development discourse is also rooted in the ecological version of modernization theory (Huber 2000). States are expected to be heavily involved in driving Western notions of innovation and entrepreneurship to stimulate economic growth as modernization theory would dictate; these states are acting within a neoliberal economic order yet are also expected to grow their economies in a sustainable way that preserves ecological resources and promotes human development and equality. Ecological modernization theory, from its inception, has emphasized the interrelated processes of "ecologizing of economy" and "economizing of ecology." With the state and industry working together through a mixture of environmental policy and ecological economics, economic development, it is argued, fosters improvements in the efficiency of resources. As such, economic development reciprocally gains from and contributes to the sustainable production and consumption of natural resources ( $M o l$ 1995). Growing economies use resources more efficiently; the efficient use of resources facilitates economic growth. Therefore, growing the economy and helping the environment are seen as interdependent processes.

Based on ecological modernization theory, the interdependence between the ecology and the economy is sometimes expressed in an inverted-U-shaped graph, which was eventually termed the environmental Kuznets curve (Stern 2004). While we do not test the specific environmental Kuznets curve, we recognize that the model suggests, in general terms, that environmental impact becomes decoupled from economic growth, or rather, economic growth is associated (at least eventually) with improving environmental conditions (Stern 2004). We underscore that this conceptual model was derived from modernization theory, in which an inverted-U shape (i.e., the original Kuznets curve from 1955) was originally used to describe the relationship between economic growth and economic inequality. Nevertheless, given its influence in the Brundtland Report and in discussions of NAFTA (Grossman and Krueger 1991; World Commission on Environment and Development 1987), the environmental version of the inverted- $U$ model exhibits a mixture of elements from neoliberalism and modernization theory. These perspectives similarly argue that economic growth and ecological improvement can feed positively into each other, as reciprocal processes of amplification.

On that note, per the modernization perspective, we can see the role equity plays in the interconnections between the three E's. Again, the original Kuznets curve suggests that economic growth will eventually reduce inequality. According to the sustainability discourse, while the argument is different from the classical model of development embraced by Kuznets, there is a positive feedback loop between economic growth and reduced inequalities (Genevey, Pachauri, and Tubiana 2013). As inequality goes down (and equality goes up), economic resources become available not only to the affluent members of society but also to lower-income communities; as a result, a greater portion of society has the resources to invest in productive (and consumptive) activities, which stimulates the overall economy 
(Voitchovsky 2009). Likewise, economic growth expands the total allotment of resources available to the country's population, reducing inequality. In summary, economic growth reduces inequality, which feeds back into and fosters further economic growth.

While the modernization framework provides this argument about the economy-equity dynamic, it also makes a proposal about the relationship between equity and ecology. Through the lens of modernization theory and Sen's capability approach, as inequality rises, social cohesion and public confidence deteriorate, undermining the organizational foundation for environmentally responsible behavior (Edwards 2005). Thus, more equal societies have the social glue to pass environmental legislation and promote widespread care for the environment. Indeed, in terms of the equity-ecology dynamic, quantitative scholars find that higher inequality results in greater ecological impact (Cushing et al. 2015). For instance, in cross-national panel models, Knight, Schor, and Jorgenson (2017) find that carbon emissions increase with inequality.

While sociologists have not studied the reverse effect (of ecology on equity), we draw from other research (e.g., Shah 2013) to propose, consistent with the above framework and the UN sustainability discourse, that increasing access to renewable technologies reduces inequality. Per the modernization framework, as countries have greater access to renewable energy, they are more capable of developing their economies without having to rely on fossil fuels. In light of the role that fossil fuel has played in the unequal ecological exchange of the world system (Grimes 1999), some environmentalists argue that renewable energy fosters a type of national development that most immediately benefits the poor, who often do not have reliable and easy access to fossil fuel (Shah 2013). According to this argument, the deployment of renewable energy around the world would not matter as much for the wealthy as it would for the impoverished. Thus, increasing access to renewable energy would not only lift people out of poverty, it would also reduce inequality, because the positive economic consequences of renewable energy are experienced by poor people more immediately than by the affluent.

\section{Modernization and Renewable Energy}

Before we summarize our hypotheses, we note that modernization theory emphasizes renewable energy as a technology to ameliorate the human impact on the planet (Toke 20II). Moreover, given the emphasis that the UN places on renewable energy in the SDGs, we acknowledge that the deployment of renewable energy is often framed as a primary sustainability strategy for local and national governments around the world (Gallagher 2013). With that said, we acknowledge the limitations of renewable energy as an ecological variable in a quantitative study: on the one hand, renewable energy represents only a fraction of the resources used by humanity and thus understates the anthropogenic impact on the environment; on the other hand, the increasing use of renewable energy has not consistently led to the desired result of reducing greenhouse gases (Thombs 2017; York 2012; York and McGee 2017). Nevertheless, given its importance in the ecological modernization literature and the emphasis placed on it by local and national governments around the world, as well as the UN, renewable energy represents a valid test of "ecology" per the modernization perspective. 


\section{Hypotheses}

To summarize the above literature review, based on the modernization framework, we propose that all two-variable combinations will be engaged in positive feedback loops with reciprocal processes of "amplification"- not negative feedback loops of "control" (Paxton, Hipp, and Marquart-Pyatt 2011). Thus, in the analysis, we are testing hypotheses of amplification, using " $\langle+>$ " to indicate that the reciprocal effects between the following variable pairs are all positive-that is, increasing the value of the one variable increases the value of the other:

Hr: Economic growth $<+>$ renewable energy consumption.

$\mathrm{H}_{2}$ : Economic growth $<+>$ economic equality.

$\mathrm{H}_{3}$ : Economic equality $<+>$ renewable energy consumption.

\section{DATA AND METHODS}

To test our hypotheses, we use country-level information, integrating data on three variables representing the three E's of sustainability: ecology, equity, and economy. These variables are renewable energy consumption as a percentage of total final energy consumption, the Gini coefficient for income inequality, and GDP per capita (in constant 2010 US dollars). All variables are log-transformed and observed between 1990 and 2015 , resulting in a total sample size of 217 (see Appendix B for a complete list). Both renewable energy and GDP per capita come from the World Bank's online World Development Indicators. The Gini coefficient for income inequality comes from the Standardized World Income Inequality Database (Solt 2016), version 6.2 of March 2018, which provides a measure of inequality in disposable (post-tax, post-transfer) income. The year 1990 was chosen as the starting point because the World Bank information on renewable energy begins that year.

Using SEM to test for reciprocal effects, we incorporate the three variables in three crosslagged models, with fixed effects (Allison, Williams, and Moral-Benito 2017; Bollen and Brand 2010). Because not every country had an observed value each year for all variables, we use full information maximum likelihood for missing values (see Appendix A for details). Figure I displays the generic model, which was used to estimate Models I to 3 below and includes four waves of data between 1990 and 2015. The four waves cover the years 1990 , 1999, 2007, 2015, with an average eight-year lag between waves. ${ }^{7}$ In an effort to minimize the number of parameters to estimate, given the small sample size, we restrict the slope estimates to be stationary across time, which assumes that the effect of each variable does not change between waves. Thus, there are four $\beta$ s to estimate (two autoregressive effects and two cross-lagged effects); allowing these slopes to vary over time would multiply the number of $\beta s$ to estimate by four between waves (see Appendix A). The latent variables Alpha and Eta represent fixed effects; their slope values are restricted to equal I (Allison, Williams, and Moral-Benito 2017). For the sake of presentation, although the concurrent covariances for the error terms at waves 2, 3, and 4 were included in the estimation, we do not display their connector lines in Figure I; correlating error terms at each wave helps guard against lag misspecification (Paul Allison, personal communication, 2018). 


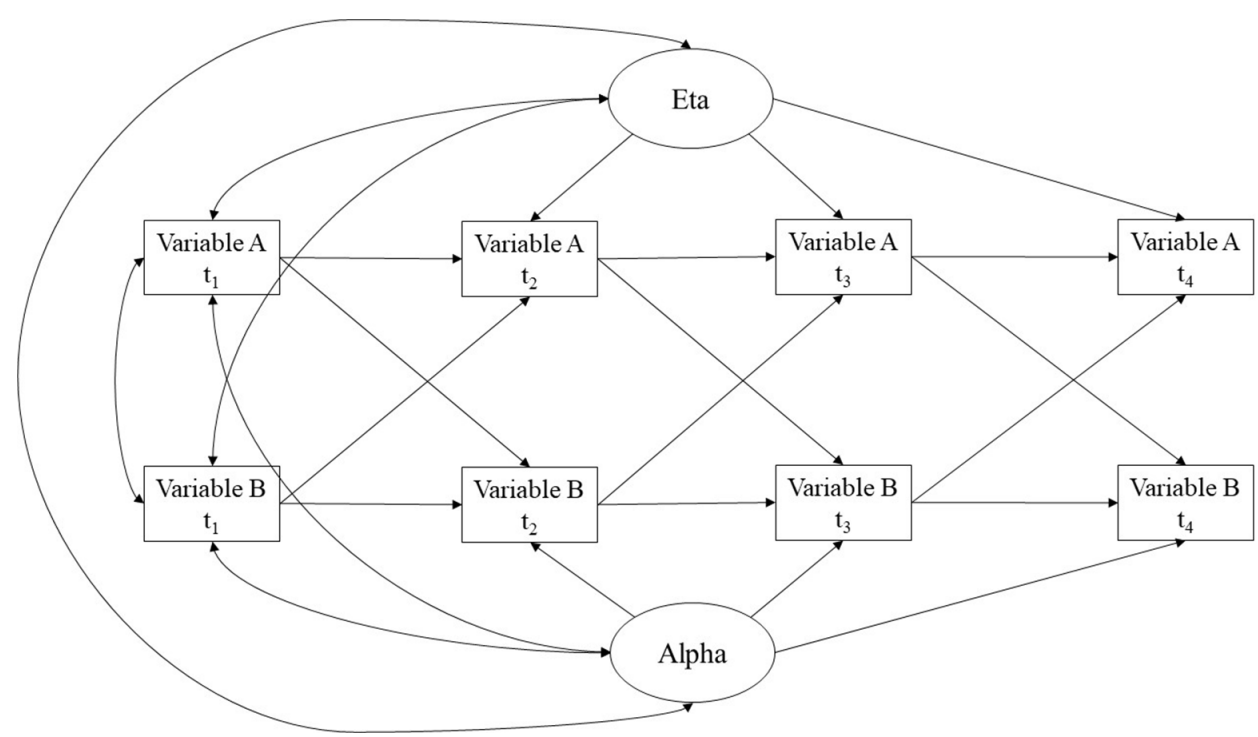

FIGURE 1. Generic two-variable cross-lagged model with four waves of data and fixed effects

Note: The estimates for the autoregressive and cross-lagged paths do not change over time. For presentation purposes, several parameters and paths used in the estimation are not drawn in the figure, including error terms (for each variable at $t_{2}, t_{3}$, and $t_{4}$ ) and concurrent correlations between error terms at $t_{2}, t_{3}$, and $t_{4}$.

\section{RESULTS AND DISCUSSION}

Summary information for the three variables is displayed in Table 2. All values are logged. The means and standard deviations reported are those used for the one-tailed paired $t$-tests, which includes only cases with values in both 1990 and 2015 . For those cases, the results from the paired $t$-tests indicate whether there was significant change over time for each variable. Between 1990 and 2015, the average values for renewable energy, Gini, and GDP per capita all increased; because the variables are logged, the change-scores reported in the table are roughly interpreted as proportional changes. Between 1990 and 2015 , renewable energy use increased by roughly $12 \%$, the Gini ratio by about $5 \%$, and GDP per capita by about $46 \%$. In other words, by the end of the I5-year time span, the typical country was using more renewable energy, had more inequality, and had experienced economic growth. While reducing inequality is a goal emphasized in the sustainability discourse, we observed an increase in inequality over time at the country level; thus, even though renewable energy use increased, these trends present mixed results with respect to the three E's of sustainability.

The SEM results are displayed in Table 3. Among three variables, there are three twovariable combinations, yielding three different cross-lagged models (with fixed effects). Model I tests the reciprocal relationship between GDP per capita and renewable energy, Model 2 looks at GDP per capita and Gini, and Model 3 is for Gini and renewable energy. For each model, we report four slope estimates: two for the two autoregressive parameters and two for the cross-lagged effects. Because the variables have been logged, each of these slopes roughly can be interpreted as an elasticity: the coefficient represents the percentage change in the outcome variable at the subsequent time period for every i percent change in the predictor variable at the preceding time period. As mentioned, to limit the number of 


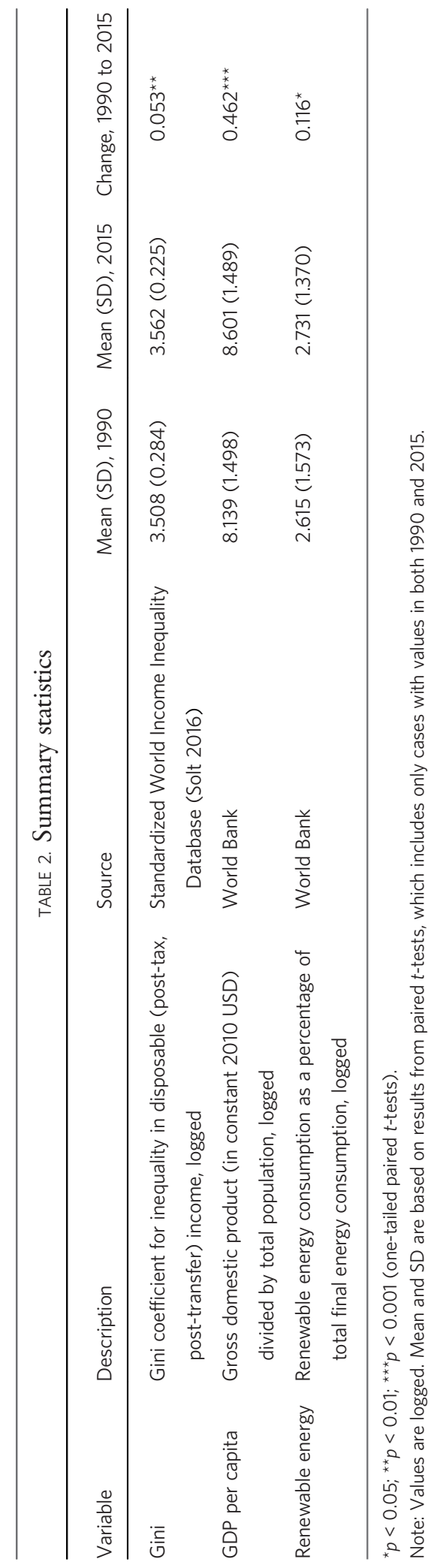




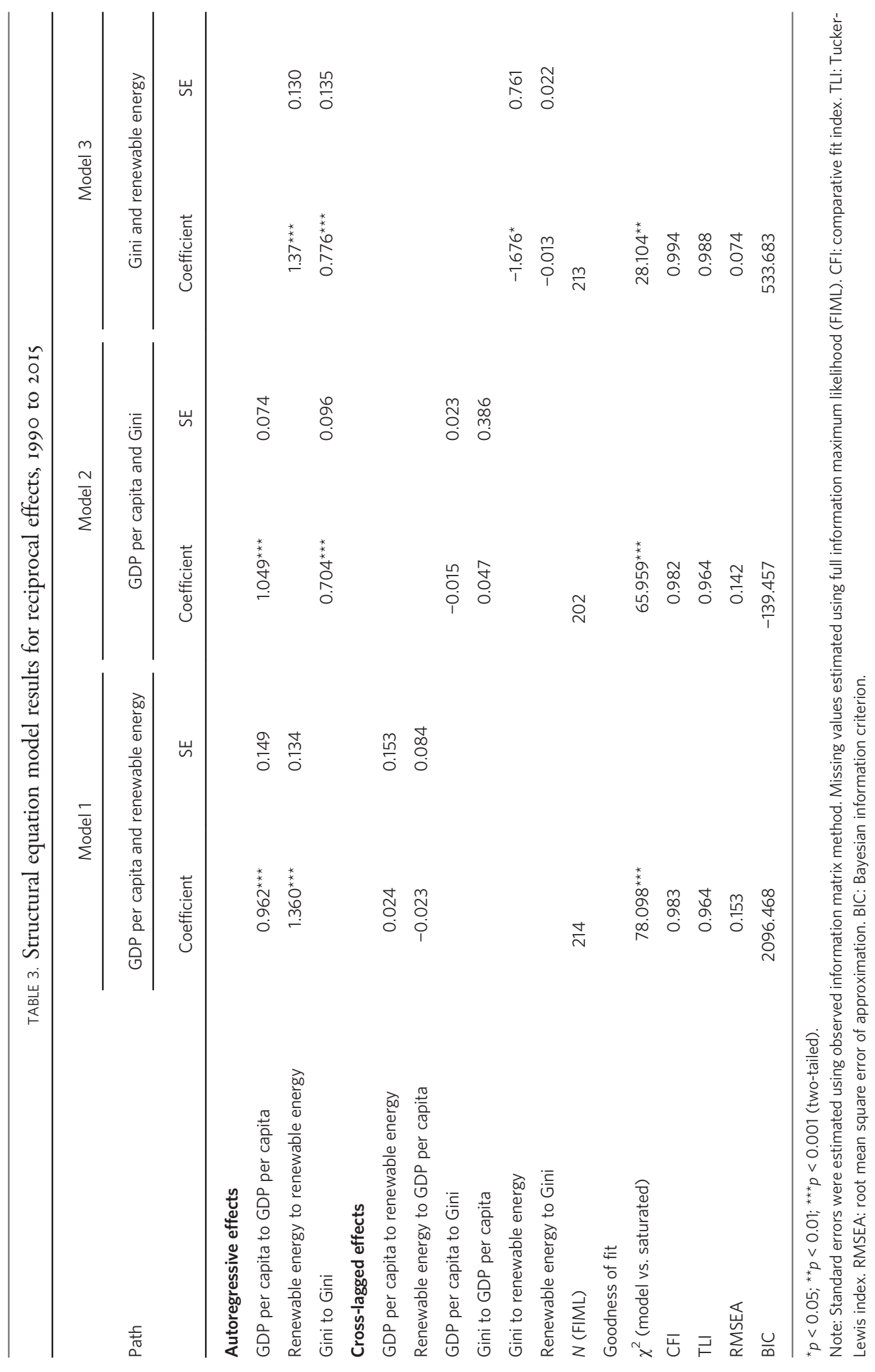


parameters to estimate, because of the small sample size, we restrict the slope estimates to be the same between waves, which assumes that the autoregressive and cross-lagged effects do not change over time. In addition to the BIC (Bayesian information criterion), we also report four statistics to compare goodness of fit between the four models: chi-squared, CFI (comparative fit index), TLI (Tucker-Lewis index), and RMSEA (root mean square error of approximation). Looking at the four comparative-fit indices, Model 3 has the lowest chi-squared and RMSEA and the highest CFI and TLI. While the chi-squared statistic is significant and the RMSEA is slightly above the 0.06 threshold, the CFI and TLI are both above 0.95 . On balance, Model 3 exhibits the best fit.

We first note that we did not find any evidence of a reciprocal relationship between these three dimensions of sustainability. In other words, according to our analysis, the three variables representing the three E's of sustainability do not feed back into each other; there is no evidence of amplification (positive feedback) or control (negative feedback). While changes in the Gini coefficient have a significant effect on renewable energy consumption, this effect is unidirectional. For all three models, the significant and positive autoregressive estimates indicate positive autocorrelation over time. We now review the results from each model reported in Table 3 .

Looking at the cross-lagged estimates from Model I, after controlling for their autoregressive effects, there is no evidence that economic growth and renewable energy are interdependent dimensions of sustainability. Contrary to the modernization perspective, economic growth is not significantly related to renewable energy use in a reciprocal manner. These results also diverge from a previous study (Apergis and Payne 2010) which found a positive bidirectional relationship between economic growth and renewable energy among OECD countries. Then in Model 2, looking at the economy-equity relationship, there is no evidence of positive feedback between economic growth and reducing inequality; in other words, economic growth did not reduce inequality, and reducing inequality did not stimulate economic growth. The lack of significant findings on the economy-equity link is not surprising, given the abundance of research on the topic, which has had mixed results, finding that growth can both increase and decrease inequality (e.g., Causa, de Serres, and Ruiz 2015) and that the effect of inequality on growth is heterogeneous (e.g., Grigoli, Paredes, and Di Bella 2016).

Not only does Model 3 exhibit the best fit, but the only significant cross-lagged effect is in that model. Following the generic form of the SEM displayed in Figure I, we display the results of Model 3 in Figure 2. For clarity, we display only the four slope coefficients (two autoregressive effects and two cross-lagged effects) and do not display all the other parameters and paths estimated in the model. ${ }^{8}$ To minimize the number of parameters to estimate, due to the sample size, the coefficients for all four paths were constrained to be stationary across time. The two autoregressive parameters are highly significant $(p<0.00 \mathrm{I})$, indicating positive temporal autocorrelation. The cross-lagged effect of renewable energy on Gini was negative $(b=-0.013)$, but it was not significant. This finding does not support the claim of some environmental scholars that the increasing deployment of renewable energy has a disproportionate benefit for impoverished communities (e.g., Shah 2013). Meanwhile, the cross-lagged effect of Gini on renewable energy was negative 

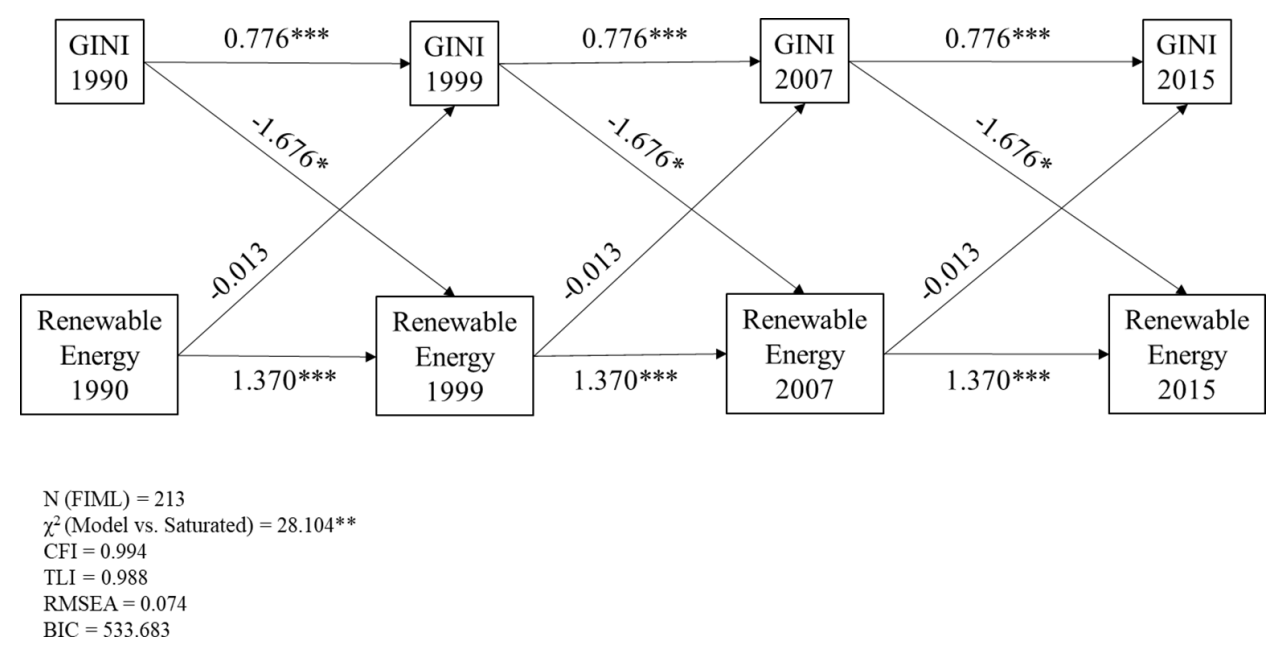

FIGURE 2. Results from Model 3: reciprocal effects between inequality and renewable energy (with fixed effects)

${ }^{*} p<0.05 ;{ }^{* *} p<0.01 ;{ }^{* * *} p<0.001$ (two-tailed).

Note: The estimates for the autoregressive and cross-lagged paths do not change over time. For presentation purposes, several parameters and paths used in the estimation are not drawn in the figure, including error terms (for each variable at $t_{2}, t_{3}$, and $t_{4}$ ) and concurrent correlations between error terms at $t_{2}, t_{3}$, and $t_{4}$. While included in the estimation, this figure also does not display Alpha and Eta for the fixed effects, their correlations, or the correlations between the exogenous variables measured in 1990 . For the full set of commands to estimate this model, including the paths and covariances not displayed, see Appendix A.

and significant $(b=-1.676 ; p<0.05)$. The negative slope indicates that over time higher inequality has a depressive effect on renewable energy consumption. As logged variables, this suggests, roughly speaking, that a I percent increase in Gini during the initial wave (or time period) is associated with a 1.676 percent decrease in renewable energy in the subsequent wave. In other words, over time, reducing inequality (i.e., raising economic equality) contributes to more renewable energy consumption, even after controlling for the autoregressive effects and other cross-lagged estimates. This result is consistent with previous environmental sociological research which finds that increasing inequality contributes to environmental degradation (e.g., Knight, Schor, and Jorgenson 2017).

To summarize, we reiterate that previous quantitative research has tended to focus on the unidirectional effects of the different dimensions of sustainability without considering the potential for these dimensions to be related reciprocally (e.g., Bradford and Stoner 2017; Causa, de Serres, and Ruiz 2015; Grigoli, Paredes, and Di Bella 2016; Knight, Schor, and Jorgenson 2017; Shandra, London, and Williamson 2003). Nevertheless, we found no evidence of a reciprocal relationship between the three E's of sustainability. Looking at the results from Model 3, while there was no statistically significant effect of renewable energy on Gini, the effect of Gini on renewable energy was statistically significant; this was the only significant cross-lagged effect from the three models. In other words, while the reciprocal relationship between renewable energy and Gini was not statistically significant, there was a significant unidirectional effect of renewable energy on Gini. 


\section{CONCLUSION}

Environmental social scientists in various disciplines have had a shared interest in the interrelation between society and the environment. While qualitative scholars have long provided answers to this question (e.g., Cronon 1992), robust quantitative methods to estimate reciprocal relationships required progress on two fronts: the availability of longitudinal data (Liu et al. 2007) and the relevant statistical tools (Allison, Williams, and Moral-Benito 2017; Bollen and Brand 2010; Paxton, Hipp, and Marquart-Pyatt 2011; Selig and Little 2012). With progress having been made on these issues, environmental scholars outside sociology have been incorporating longitudinal data into cross-lagged (or bidirectional) models to examine the interdependent relationship between the social and environmental dimensions of sustainability (Apergis and Payne 2010; Lund and Cois 2018; Richter, Thøgersen, and Klöckner 2017). We situate our project in this emerging literature.

More specifically, for the discipline of sociology, this project represents an effort to advocate the analysis of reciprocal effects as a relevant tool for scholars developing and testing theoretical frameworks for sustainable development. For this initial effort, we focused on modernization theory and its influence on the UN approach to sustainability, which explicitly states that the three E's of sustainable development are reciprocally related. In our assessment of modernization theory, we do not intend to engage in the ongoing debate within sociology (e.g., Foster 2012); rather, we draw on this framework not only because of its role in the sustainable development discourse (e.g., Huber 2000) but also to demonstrate the utility of a reciprocal effects analysis for future environmental research in sociology.

To that end, we incorporated three country-level variables (representing the three E's of sustainability) into cross-lagged SEMs (with fixed effects). For the years 1990 through 2015, we did not find any evidence of reciprocal effects. Nevertheless, we did find that greater equality results in more renewable energy consumption (as a percentage of total final energy consumption). This result is consistent with previous environmental research on the independent effect of inequality in conventional panel models (e.g., Knight, Schor, and Jorgenson 2017). In the conclusion we elaborate on the theoretical and policy implications of these findings, but first we review two limitations of our analysis.

First, as detailed in Appendix A, our relatively small sample size restricted the number of waves and precluded testing whether the effects change over time. For the same reason, we also did not incorporate control variables. While these models control for autoregressive effects, future scholarship using bigger sample sizes will be better suited to incorporate additional waves of data, allow the slope estimates to vary between waves, and consider whether to include control variables. Making use of these techniques would yield more robust results for assessing whether the dimensions of sustainability are reciprocally related over time at lower levels of analysis.

Second, our analysis focused on only three variables representing the three E's of sustainability. Clearly, there are other measures that represent ecology, economy, and equity. For instance, while income inequality is consistently tracked across time and space for developed and developing nations, Knight, Schor, and Jorgenson (2017) argue that wealth inequality should also be treated as a measure of equity in studies looking at its environmental impact. As the authors note, not only is inequality in wealth greater than inequality in income, but 
measures of wealth better represent access to political, economic, and natural resources. Also, while renewable energy, like income inequality, has the advantage of more consistent and greater coverage over time and space, as a measure of ecology, it does not include the environmental impacts embedded in the production and consumption of resources. On this note, some scholars argue that the ecological footprint would be a more comprehensive measure of environmental impact. Moreover, while renewable energy is often framed as a technology to battle climate change, there is inconsistent evidence to support this claim (Thombs 2017; York 2012; York and McGee 2017). All the same, considering the emphasis on renewable energy in the modernization literature and its prominent role in the UN's SDGs, renewable energy is a valid measure to test whether ecology is a reciprocal dimension of sustainability.

With these limitations in mind, we emphasize that this study makes important contributions to the literature, with implications for theory and policy. We presented an analytic technique to test a core assumption underpinning the discourse on state governance concerning sustainable development: that the 17 SDGs and their targets are interconnected. In addition, we used longitudinal SEMs to test reciprocal relationships, a robust analytic technique that estimates the cross-lagged effects for a combination of variables while controlling for temporal autocorrelation within each variable. Engaging in this analytic strategy lays the groundwork for future socio-ecological research on whether there are reciprocal relationships between the different dimensions of sustainability. Future research testing the assumption that the SDGs are interrelated is warranted, but it might benefit from longitudinal designs with a wider variety of variables to operationalize measures of equity, economy, and ecology. In addition, research at multiple levels of analysis (provincial, state, county, municipal, individual, etc.) and with larger sample sizes might reveal reciprocal effects we did not find at the national level. There already exists a literature on socio-ecological dynamics at the individual level, as well as municipal government activity promoting sustainable development, that could be consulted (e.g., Lund and Cois 2018; Saha and Paterson 2008).

If future research similarly finds no reciprocal effects, the UN and other development actors might want to rethink the assumptions underpinning the SDGs for the design of government policies and other development activities. Perhaps the modern form of neoliberal development has constrained the potential for the sustainability goals to feed back into each other. In the current study we found that inequality increased between 1990 and 2015 , even though economic growth increased over the same period. While the three E's are meant to be given equal weight, Gunder (2006) contends that policy planners tend to overly emphasize the economic side. This is apparent in the formulation of the MDGs, and of the SDGs that replaced them. Certainly, there are differences between the two sets of goals, but, as Weber (2014:129-30) notes, "both share problematic, ahistorical, and non-relational understandings of poverty and development, and the ways in which they are closely tied into neoliberal political approaches to development." Weber also argues, for example, that the SDGs emphasize neoliberal notions of market access to public goods such as water and healthcare, reducing these goods to commodities and ensuring unequal access to basic needs.

Also, within the SDGs, development is conceptualized as a hierarchical process. Countries are ranked relative to one another based on various inequalities, as if the countries are 
at different heights on a ladder (Weber 20I4). This ladder can have no end, because underdevelopment is measured relative to the countries at the top. This approach ignores that unequal social relations have historically been politically enabled, and social movement politics are viewed as external variables rather than an integral part of the political dynamics of development (Weber 2014). Relatedly, a number of the SDGs are related to strengthening governance mechanisms, which could be used to justify policies that further marginalize, exclude, and criminalize minority populations and social movements, thus deepening inequality even further (Blaustein et al. 2018; Weber 2014).

Meanwhile, the assumption of economic growth has served a primary role in modernization theory. Indeed, not only has it become a central component in the framework used by the development community to address the "equity" and "ecology" of sustainability, but economic growth has also become a part of "middle class consciousness" (Nandy 2002), as a development technique supported by the population in general. All the same, considering that sustainability is an elastic and contested concept (Longo et al. 2016), the rhetoric of sustainable development can be used as a justification for unsustainable political priorities. Given the finding that greater equality results in more renewable energy consumption, and that economic growth does not consistently lead to reductions in inequality, development actors and policy planners should focus less on neoliberal policies (which prioritize economic growth and governance initiatives that strengthen coercive public and private institutions of social control) and more on ecologically sustainable initiatives that foster social cohesion and public confidence.

\section{APPENDIX A. NOTES ON SAMPLE SIZE IN LONGITUDINAL DATA ANALYSIS USING STRUCTURAL EQUATION MODELING}

Using SEM for longitudinal data analysis, where the data are organized in wide form, is different from conventional panel modeling, where the data are organized in long form. For the purposes of our paper, one of the most important differences between SEM and conventional panel modeling concerns what happens to the effective sample size as additional waves (or time periods) of data are incorporated into the model. For conventional panel models, each additional wave of data increases the unit-period number of observations used in the model. For instance, if you have a balanced panel of 100 nations, two years of data yields an effective sample size of 200 nation-years, three years of data gives you 300 nation-years, and so on. Thus, all else equal, and roughly speaking, incorporating more time periods into a conventional panel model gives you more degrees of freedom, which allows you to estimate more parameters (e.g., control variables) with confidence that you have minimized potential statistical bias (due to the ratio of sample size to the number of parameters being estimated).

This is not the case when using SEM for longitudinal data analysis. No matter how many waves of data, the effective sample size is the same. In fact, without certain constraints, each additional time period creates another set of parameters to estimate. For instance, if you have a longitudinal SEM with one predictor variable having only a direct effect on a single dependent variable, for two years of data, you have one slope to 
estimate; for three years, there are two slopes, and so on. The same also happens for each additional predictor variable incorporated into the model. Thus, for instance, in a model with two predictor variables and two time periods, there are two (direct effect) slopes to estimate; with two predictors and three time periods, there are four slopes; and so on. Not including SEM's estimates of the intercepts, the co-variances, and so on, for a longitudinal model estimating only direct effects, the number of slopes (i.e., direct effects) to estimate is $k$ (the number of predictor variables) times $t-\mathrm{I}$ (the number of time periods minus one).

Meanwhile, in our project we use SEM to estimate a cross-lagged model with reciprocal effects. After the first wave with two exogenous variables, for each additional time period incorporated into the model, there are four more slopes to estimate. With four waves of data, the number of parameters to estimate is $4 \times(4-\mathrm{I})=\mathrm{I} 2$ (again not including estimates for intercepts, co-variances, etc.). Given that we have a maximum of 214 nations in Model I (by full information maximum likelihood; more on this below), this would yield a sample size to slope estimate ratio of 21 4:12, or about I 8 cases for each slope estimate. To improve this ratio, we have constrained the slope estimates not to vary between waves. Thus, instead of 12 , there are only 4 slopes to estimate, or about 50 cases for each slope estimate, which is above the recommended minimum to avoid estimation problems in structural equation models (Kline 2015).

For longitudinal SEM, adding control variables, like time periods, means more parameters to estimate. In our analysis, given that the slopes are constrained not to change over time, if a single control variable is presumed to have an independent effect on both of the two primary (endogenous) variables and also have an autoregressive parameter, adding that single variable would create three more slopes to estimate. If the slopes don't change over time, a two-variable cross-lagged, reciprocal effects model with one control variable has seven parameters to estimate (again not including estimates for co-variances, etc.), or about 30 cases for each slope estimate. Adding a second control variable, with the same conditions, would mean about 20 cases for each slope estimate, and so on.

To reiterate, adding more waves of data to a longitudinal SEM does not increase the number of unit-period observations as it does in conventional panel models. With that in mind, and given that our maximum sample size is 214 , in an effort to minimize any statistical problems of bias with SEM, we do not incorporate control variables and restrict the four slope estimates to be stationary across the different waves.

To estimate these models, we use the SEM suite of commands in Stata. For missing values, Stata's SEM procedure allows the option method(mlmv) (maximum likelihood with missing values). Using ml mv, cases with missing values are not deleted unless the case is missing observations entirely for all variables in the model. If a case has at least one observation for one variable, it is not excluded from the estimation of the model. (More information about the mlmv option can be found in Stata's SEM refence manual.) Thus, the number of observations changes slightly for each model we estimate. For instance, of the 217 nations recognized by the UN, three are missing observations entirely and thus excluded from Model I, fifteen from Model 2, and four from Model 3. The list of nations for the study and which models they are excluded from is found in Appendix B. 
For transparency and to promote the utility of a reciprocal effects approach for future scholarship, we are sharing the commands used to estimate Model 3. The following was run from a . do file in Stata:

sem $/ / /$

(lnrenewi990@a lnsolti990@b Alpha@r -> lnrenewi999) ///

(lnrenew1999@alnsolti999@b Alpha@i -> lnrenew2007) ///

(lnrenew2007@alnsolt2007@b.Alpha@r -> lnrenew2015)///

(lnsoltr990@clnrenewi990@dEta@r -> lnsolti999) ///

(lnsolt1999@clnrenewi999@dEta@i ->lnsolt2007)///

(lnsolt2007@clnrenew2007@dEta@i ->lnsolt2015),///

$\operatorname{method}(\mathrm{mlmv})$ difficult ///

latent(Alpha Eta) ///

covstruct(_lexogenous, diagonal) ///

$\operatorname{cov}($ lnsolti990*lnrenewi990) ///

cov(e.lnsoltr999*e.lnrenewi999 e.lnsolt2007*e.lnrenew2007 e.lnsolt2015*e.lnrenew2015) ///

cov(Alpha*Eta Alpha*lnsoltı990 Alpha*Inrenewı990 Eta*lnsoltı990 Eta*lnrenewi990)

${ }^{* * *}$ Note: The two variables in this model are lnrenew and lnsolt (the natural log of renewable energy and the natural log of Solt's inequality measure). In the suffix, we use the fournumber year to denote the time period. For example, lnrenewi990 is the natural log of renewable energy for the year 1990 .

\section{APPENDIX B. NATIONS INCLUDED IN THE STUDY}

The following are all 217 of the nations included in the study. As detailed in Appendix A, for the analysis in Stata, we use the SEM option mlmv (maximum likelihood with missing values), which excludes cases only if they are completely missing values for all variables and time periods in the model being estimated. In the list below, if a country was excluded from a model, we identify that model in parentheses.

$\begin{array}{lll}\text { Afghanistan } & \text { Bangladesh } & \text { Bulgaria } \\ \text { Albania } & \text { Barbados } & \text { Burkina Faso } \\ \text { Algeria } & \text { Belarus } & \text { Burundi } \\ \text { American Samoa } & \text { Belgium } & \text { Cabo Verde } \\ \text { Andorra } & \text { Belize } & \text { Cambodia } \\ \text { Angola } & \text { Benin } & \text { Cameroon } \\ \text { Antigua and Barbuda } & \text { Bermuda } & \text { Canada } \\ \text { Argentina } & \text { Bhutan } & \text { Cayman Islands (Model 2) } \\ \text { Armenia } & \text { Bolivia } & \text { Central African Republic } \\ \text { Aruba (Model 2) } & \text { Bosnia and Herzegovina } & \text { Chad } \\ \text { Australia } & \text { Botswana } & \text { Channel Islands } \\ \text { Austria } & \text { Brazil } & \text { (Models 1, 2, 3) } \\ \text { Azerbaijan } & \text { British Virgin Islands } & \text { Chile } \\ \text { Bahamas, The } & \text { (Model 2) } & \text { China } \\ \text { Bahrain } & \text { Brunei Darussalam } & \text { Colombia }\end{array}$




\begin{tabular}{|c|c|c|}
\hline Comoros & Indonesia & Mozambique \\
\hline Congo, Dem. Rep. & Iran, Islamic Rep. & Myanmar \\
\hline Congo, Rep. & Iraq & Namibia \\
\hline Costa Rica & Ireland & Nauru \\
\hline Cote d'Ivoire & Isle of Man & Nepal \\
\hline Croatia & Israel & Netherlands \\
\hline Cuba & Italy & New Caledonia (Model 2) \\
\hline Curacao (Model 2) & Jamaica & New Zealand \\
\hline Cyprus & Japan & Nicaragua \\
\hline Czech Republic & Jordan & Niger \\
\hline Denmark & Kazakhstan & Nigeria \\
\hline Djibouti & Kenya & Northern Mariana Islands \\
\hline Dominica & Kiribati & Norway \\
\hline Dominican Republic & Korea, Dem. People's Rep. & Oman \\
\hline Ecuador & (Model 2) & Pakistan \\
\hline Egypt, Arab Rep. & Korea, Rep. & Palau \\
\hline El Salvador & Kosovo & Panama \\
\hline Equatorial Guinea & Kuwait & Papua New Guinea \\
\hline Eritrea & Kyrgyz Republic & Paraguay \\
\hline Estonia & Lao PDR & Peru \\
\hline Ethiopia & Latvia & Philippines \\
\hline Faroe Islands (Model 2) & Lebanon & Poland \\
\hline Fiji & Lesotho & Portugal \\
\hline Finland & Liberia & Puerto Rico \\
\hline France & Libya & Qatar \\
\hline French Polynesia (Model 2) & Liechtenstein (Model 2) & Romania \\
\hline Gabon & Lithuania & Russian Federation \\
\hline Gambia, The & Luxembourg & Rwanda \\
\hline Georgia & Macao SAR, China & Samoa \\
\hline Germany & Macedonia, FYR & San Marino (Model 3) \\
\hline Ghana & Madagascar & Sao Tome and Principe \\
\hline Gibraltar (Model 2) & Malawi & Saudi Arabia \\
\hline Greece & Malaysia & Senegal \\
\hline Greenland & Maldives & Serbia \\
\hline Grenada & Mali & Seychelles \\
\hline Guam & Malta & Sierra Leone \\
\hline Guatemala & Marshall Islands & Singapore \\
\hline Guinea & Mauritania & Sint Maarten, Dutch part \\
\hline Guinea-Bissau & Mauritius & (Model 2) \\
\hline Guyana & Mexico & Slovak Republic \\
\hline Haiti & Micronesia, Fed. Sts. & Slovenia \\
\hline Honduras & Moldova & Solomon Islands \\
\hline Hong Kong SAR, China & Monaco (Models 1, 2, 3) & Somalia (Model 2) \\
\hline Hungary & Mongolia & South Africa \\
\hline Iceland & Montenegro & South Sudan \\
\hline India & Morocco & Spain \\
\hline
\end{tabular}




$\begin{array}{lll}\text { Sri Lanka } & \text { Tanzania } & \text { United Kingdom } \\ \text { St. Kitts and Nevis } & \text { Thailand } & \text { United States } \\ \text { St. Lucia } & \text { Timor-Leste } & \text { Uruguay } \\ \text { St. Martin, French part } & \text { Togo } & \text { Uzbekistan } \\ \quad \text { Models 1, 2, 3) } & \text { Tonga } & \text { Vanuatu } \\ \text { St. Vincent and the } & \text { Trinidad and Tobago } & \text { Venezuela, B. R. } \\ \text { Grenadines } & \text { Tunisia } & \text { Vietnam } \\ \text { Sudan } & \text { Turkey } & \text { Virgin Islands, U.S. } \\ \text { Suriname } & \text { Turkmenistan } & \text { West Bank and Gaza } \\ \text { Swaziland } & \text { Turks and Caicos Islands } & \text { Yemen, Rep. } \\ \text { Sweden } & \text { Tuvalu } & \text { Zambia } \\ \text { Switzerland } & \text { Uganda } & \text { Zimbabwe } \\ \text { Syrian Arab Republic } & \text { Ukraine } & \\ \text { Tajikistan } & \text { United Arab Emirates } & \end{array}$

\section{REFERENCES}

Allison, Paul D. 2009. Fixed Effects Regression Models. Los Angeles, CA: SAGE.

Allison, Paul D., Richard Williams, and Enrique Moral-Benito. 2017. "Maximum Likelihood for CrossLagged Panel Models with Fixed Effects." Socius 3:1-17.

Apergis, Nicholas, and James E. Payne. 2010. "Renewable Energy Consumption and Economic Growth: Evidence from a Panel of OECD Countries.” Energy Policy 38(1):656-60.

Austin, Kelly F., and Laura A. McKinney. 2016. "Disaster Devastation in Poor Nations: The Direct and Indirect Effects of Gender Equality, Ecological Losses, and Development." Social Forces 95(1): $355-80$.

Blaustein, Jarrett, Nathan W. Pino, Kate Fitz-Gibbon, and Rob White. 2018. "Criminology and the UN Sustainable Development Goals: The Need for Support and Critique." British Journal of Criminology 58(4):767-86.

Bollen Kenneth A., and Jennie E. Brand. 2010. "A General Panel Model with Random and Fixed Effects: A Structural Equations Approach.” Social Forces 89:1-34.

Bradford, John Hamilton, and Alexander M. Stoner. 2017. "The Treadmill of Destruction in Comparative Perspective: A Panel Study of Military Spending and Carbon Emissions, 1960-2014." Journal of World-Systems Research 23(2):298-325.

Burns, Thomas J., Edward I. Kick, David A. Murray, and Dixie Murray. 1994. "Demography, Development and Deforestation in a World-System Perspective." International Journal of Comparative Sociology 35:221-39.

Catton, William R., and Riley E. Dunlap. 1978. "Environmental Sociology: A New Paradigm." American Sociologist 13:41-49.

Causa, Orsetta, Alain de Serres, and Nicolas Ruiz. 2015. "Can Pro-growth Policies Lift All Boats? An Analysis Based on Household Disposable Income.” OECD Journal: Economic Studies 1:227-68.

Cronon, William. 1992. Nature's Metropolis. New York: Norton.

Cushing, Laura, Rachel Morello-Frosch, Madeline Wander, and Manuel Pastor. 2015. "The Haves, the Have-nots, and the Health of Everyone: The Relationship between Social Inequality and Environmental Quality." Annual Review of Public Health 36:193-209.

Edwards, Andres R. 2005. The Sustainability Revolution: Portrait of a Paradigm Shift. Gabriola Island, BC: New Society.

Elliott, James R., and Matthew Thomas Clement. 2017. "Natural Hazards and Local Development: The Successive Nature of Landscape Transformation in the United States." Social Forces 96(2): 851-76. 
Foster, John Bellamy. 2012. "The Planetary Rift and the New Human Exemptionalism: A Political Economic Critique of Ecological Modernization Theory." Organization and Environment 25:211-237.

Fukuda-Parr, Sakiko. 2003. "The Human Development Paradigm: Operationalizing Sen's Ideas on Capability." Feminist Economics 9(2-3):301-17.

Fukuda-Parr, Sakiko. 2004. "Millennium Development Goals: Why They Matter." Global Governance 10(4):395-402.

Gallagher, Kelly Sims. 2013. "Why and How Governments Support Renewable Energy." Daedalus 142:59-77.

Genevey, Rémi, R. K. Pachauri, and Laurence Tubiana. 2013. Reducing Inequalities: A Sustainable Development Challenge. Paris: Energy and Resources Institute.

Grigoli, Francesco, Evelio Paredes, and Gabriel Di Bella. 2016. "Inequality and Growth: A Heterogeneous Approach.” Working Paper WP/16/244, International Monetary Fund.

Grimes, Peter E. 1999. "The Horsemen and the Killing Fields: The Final Contradiction of Capitalism." Pp. 13-42 in Ecology and the World-System. edited by Walter L. Goldfrank, David Goodman, and Andrew Szasz. Westport, CT: Greenwood Press.

Grossman, Gene M., and Alan B. Krueger. 1991. "Environmental Impacts of a North American Free Trade Agreement.” Working Paper 3914, National Bureau of Economic Research, Cambridge, MA.

Gunder, Michael. 2006. “Sustainability: Planning's Saving Grace or Road to Perdition?” Journal of Planning Education and Research 26(2):208-21.

Huber, Joseph. 2000. "Towards Industrial Ecology: Sustainable Development as a Concept of Ecological Modernization." Journal of Environmental Policy and Planning 2(4):1-28.

International Council for Science and International Social Science Council. 2015. Review of the Sustainable Development Goals: The Science Perspective. Paris: International Council for Science.

Jorgenson, Andrew K. 2003. "Consumption and Environmental Degradation: A Cross-national Analysis of the Ecological Footprint.” Social Problems 50(3):374-94.

Jorgenson, Andrew K., and Brett Clark. 2012. "Are the Economy and the Environment Decoupling? A Comparative International Study, 1960-2005.” American Journal of Sociology 118(1):1-44.

Kick, Edward L., and Laura A. McKinney. 2014. "Global Context, National Interdependencies, and the Ecological Footprint: A Structural Equation Analysis.” Sociological Perspectives 57(2):256-79.

Kick, Edward L., Laura McKinney, and Gretchen H. Thompson. 2011. "Intensity of Food Deprivation: The Integrative Impacts of the World System, Modernization, Conflict, Militarization and the Environment." Sociological Perspectives 52(6):478-502.

Kline, Rex B. 2015. Principles and Practice of Structural Equation Modeling. 4th ed. New York: Guilford.

Knight, Kyle W., Juliet B. Schor, and Andrew K. Jorgenson. 2017. "Wealth Inequality and Carbon Emissions in High-income Countries." Social Currents 4(5):403-12.

Kuznets, Simon. 1955. "Economic Growth and Income Inequality." American Economic Review 45(1): $1-28$.

Le Blanc, David. 2015. "Towards Integration at Last? The Sustainable Development Goals as a Network of Targets." Sustainable Development 23:176-87.

Liu, J., T. Dietz, S. R. Carpenter, M. Alberti, C. Folke, M. Alberti, C. L. Redman, S. H. Schneider, E. Ostrom, A. N. Pell, J. Lubchenco, W. W. Taylor, Z. Ouyang, P. Deadman, T. Kratz, and W. Provencher. 2007. "Coupled Human and Natural Systems." Ambio 36(8):639-49.

Longo, Stefano B., Brett Clark, Thomas E. Shriver, and Rebecca Clausen. 2016. "Sustainability and Environmental Sociology: Putting the Economy in Its Place and Moving toward an Integrative SocioEcology.” Sustainability 8(5):437 (doi:10.3390/su8050437).

Lund, Crick, and Annibale Cois. 2018. "Simultaneous Social Causation and Social Drift: Longitudinal Analysis of Depression and Poverty in South Africa." Journal of Affective Disorders 229:396-402.

McCollum, David L., Luis Gomez Echeverri, Sebastian Busch, Shonali Pachauri, Simon Parkinson, Joeri Rogelj, Volker Krey, Jan C. Minx, Måns Nilsson, Anne-Sophie Stevance, and Keywan Riahi. 2018. 
"Connecting the Sustainable Development Goals by Their Energy Inter-linkages." Environmental Research Letters 13(3):1-23.

Mol, Arthur P. J. 1995. The Refinement of Production. Utrecht: Van Arkel.

Nandy, Ashis. 2002. "The Beautiful, Expanding Future of Poverty: Popular Economics as a Psychological Defense." International Studies Review 4(2):107-21.

Passerini, Eve. 1998. "Sustainability and Sociology." American Sociologist 29(3):59-70.

Paxton, Pamela M., John R. Hipp, and Sandra Marquart-Pyatt. 2011. Nonrecursive Models: Endogeneity, Reciprocal Relationships, and Feedback Loops. Thousand Oaks, CA: SAGE.

Richter, Isabell, John Thøgersen, and Christian A. Klöckner. 2017. "Sustainable Seafood Consumption in Action: Relevant Behaviors and their Predictors." Sustainability 9(12):2313.

Robeyns, Ingrid. 2005. “The Capability Approach: A Theoretical Survey.” Journal of Human Development 6(1):93-117.

Rosa, Eugene, A., Thomas K. Rudel, Richard York, Andrew K. Jorgenson, and Thomas Dietz. 2015. "The Human (Anthropogenic) Driving Forces of Global Climate Change." Pp. 32-60 in Climate Change and Society: Sociological Perspectives. edited by Riley Dunlap and Robert Brulle. Oxford: Oxford University Press.

Saha, Davashree, and Robert G. Paterson. 2008. "Local Government Efforts to Promote the 'Three Es' of Sustainable Development: Survey in Medium to Large Cities in the United States." Journal of Planning Education and Research 28:21-37.

Schnaiberg, Allan. 1975. "Social Syntheses of the Societal-Environmental Dialectic: The Role of Distributional Impacts.” Social Science Quarterly 56:5-20.

Selig, James P., and Todd D. Little. 2012. "Autoregressive and Cross-Lagged Panel Analysis for Longitudinal Data." Pp. 265-78 in Handbook of Developmental Research Methods. edited by Brett Laursen, Todd D. Little, and Noel A. Card. New York: Guildford Press.

Sen, Amartya. 1973. On Economic Inequality. Oxford: Oxford University Press.

Sen, Amartya. 1999. Development as Freedom. Oxford: Oxford University Press.

Sen, Amartya. 2011. The Idea of Justice. Cambridge, MA.: Harvard University Press.

Shah, Jigar. 2013. Creating Climate Wealth: Unlocking the Impact Economy. Denver, CO: ICOSA.

Shandra, John M., Bruce London, and John B. Williamson. 2003. "Environmental Degradation, Environmental Sustainability, and Overurbanization in the Developing World: A Quantitative, CrossNational Analysis." Sociological Perspectives 46(3):309-32.

Solt, Frederick. 2016. "The Standardized World Income Inequality Database." Social Science Quarterly $97(5): 1267-81$.

Stern, David. 2004. "The Rise and Fall of the Environmental Kuznets Curve." World Development 32(8):1419-39.

Thombs, Ryan P. 2017. "The Paradoxical Relationship between Renewable Energy and Economic Growth: A Cross-national Panel Study, 1990-2013.” Journal of World-Systems Research 23(2): 540-64.

Thombs, Ryan P. 2018. “The Transnational Tilt of the Treadmill and the Role of Trade Openness on Carbon Emissions: A Comparative International Study, 1965-2010.” Sociological Forum 33(2): 422-42.

Toke, David. 2011. “Ecological Modernisation, Social Movements and Renewable Energy." Environmental Politics 20(1):60-77.

Tosun, Jale, and Julia Leininger. 2017. "Governing the Interlinkages between the Sustainable Development Goals: Approaches to Attain Policy Integration.” Global Challenges 1(9) (doi:10.1002/ gch2.201700036).

United Nations Development Programme. 1990. Human Development Report. New York: Oxford University Press.

United Nations Development Programme. 2019. "Sustainable Development Goals" (https://www. undp.org/content/undp/en/home/sustainable-development-goals.html). 
United Nations Economic and Social Council. 2018. "President's Summary of the 2018 High-Level Political Forum on Sustainable Development" (https://sustainabledevelopment.un.org/content/ documents/205432018_HLPF_Presidents_summary_FINAL.pdf).

United Nations General Assembly Resolution 70/1, Transforming Our World: The 2030 Agenda for Sustainable Development, A/RES/70/1 (25 September 2015) (https://sustainabledevelopment.un. org/post2015/transformingourworld).

United Nations General Assembly Resolution 55/2, United Nations Millennium Declaration, A/55/L.2 (8 September 2000) (http://www.un.org/millennium/declaration/ares552e.htm).

United Nations Information Service. 2015. "Press Kit for the Sustainable Development Summit 2015: Time for Global Action for People and Planet” (http://www.unis.unvienna.org/pdf/2015/FAQs Sustainable_Development_Summit_final.pdf).

Voitchovsky, Sarah. 2009. "Inequality, Growth and Sectoral Change." Chapter 22 in Oxford Handbook of Economic Inequality. edited by Brian Nolan, Wiemer Salverda, and Timothy M. Smeeding. Oxford: Oxford University Press.

Weber, Heloise. 2014. "When Goals Collide: Politics of the MDGs and the Post-2015 Sustainable Development Goals Agenda." SAIS Review of International Affairs 34(2):129-39.

World Commission on Environment and Development. 1987. Our Common Future. New York: United Nations.

World Health Organization. 2015. “From MDGs to SDGs: A New Era in Global Health” (http://www. who.int/about/finances-accountability/funding/financing-dialogue/MDGstoSDGs_Summary.pdf).

York, Richard. 2012. "Do Alternative Energy Sources Displace Fossil Fuels?" Nature Climate Change 2:441-43.

York, Richard, and Julius A. McGee. 2017. "Does Renewable Energy Development Decouple Economic Growth from $\mathrm{CO}_{2}$ Emissions?” Socius 3:1-6.

York, Richard, Eugene Rosa, and Thomas Dietz. 2003. "Footprints on the Earth: The Environmental Consequences of Modernity." American Sociological Review 68:279-300.

\section{NOTES}

I. As discussed by Longo et al. (2016), the concept of the three E's of sustainability is also known as the "sustainable development triangle," sustainability's "three-legged stool," the "three pillars of sustainability," and the "triple bottom line."

2. As in common in the literature, we use this abbreviation for both "structural equation models" and "structural equation modeling."

3. We recognize that the sociological literature has long evaluated competing theoretical perspectives on sustainability and development (e.g., Longo et al. 2016; York, Rosa, And Dietz 2003). We focus our analysis on modernization theory because of its influence on the sustainability discourse. Also, because we intend to demonstrate the utility of SEM for the analysis of reciprocal effects, we refrain from diving more deeply into the vast sociological literature on sustainability and modern development (e.g., Austin and McKinney 2016; Burns et al. 1994; Jorgenson 2003; Jorgenson and Clark 2012; Kick and McKinney 2014; Kick, McKinney, and Thompson 2011; Rosa et al. 2015; Thombs 2017 and 2018; York and McGee 2017); we hope that our analysis serves as motivation for future scholarship to do so.

4. The forum was created in 2012 as a UN commission and convened annually since 2013 to evaluate and review progress on the 2030 Agenda on Sustainable Development.

5. The joint report is a nuanced, comprehensive and constructive critique of the interconnections between the SDGs. In fact, in their review, these social and natural scientists recognize that not at all targets will be mutually reinforcing (or what, in the language of SEM, Paxton, Hipp, and MarquartPyatt [20II] call a process of "amplification"); rather, achieving one target may impose a constraint on another target (or what Paxton, Hipp, and Marquart-Pyatt would call a process of "control"). 
6. Elliott and Clement (2017) did not use fixed effects in their SEM analysis. As with conventional panel models, fixed effects in SEM help minimize omitted variable bias by controlling for unobservable factors that are time-invariant-that is, features unique to each case that do not change during the time interval being studied (Allison 2009).

7. Here we make two comments about the lag time between waves. First, we intended to cover the broadest range of years for which information is available on all three variables in the analysis. Given that the World Bank renewable energy data begin in 1990 and end in 2015 , this period was used for the analysis. (The International Energy Agency provides longer coverage, but access to the data is restricted.) In preliminary analyses, we added waves to reduce the lag time; however, in doing this, the estimation procedure did not converge. Thus, we continued to remove waves (thereby extending the lag time) until the estimation procedure converged for the three models reported. Because we want to ensure that the sample covers the full range of years between 1990 and 2015 , reducing the number of waves increases the lag between waves and also results in fewer parameters to estimate. Our goal was to maintain coverage for the entire interval between 1990 and 2105. As mentioned above, reducing the lag resulted in additional waves, and the models did not converge. Ultimately, all three models converged when using the same four time periods (1990, 1999, 2007, 2015), which yielded an eight-year average lag. Second, considering the exploratory nature of this project, we emphasize that sociologists conducting environmental research have not established any standards for specifying the time lag in quantitative research. Certainly, when examining exogenous effects of predictor variables, many scholars have used longitudinal panel models with a one-year lag for the dependent variable (e.g., Bradford and Stoner 2017; Shandra, London, and Williamson 2003). We would have preferred a lag shorter than eight years, but as mentioned, the small sample size, in combination with the sensitivity of a cross-lagged SEM (with fixed effects), precluded the use of additional waves. We therefore encourage future scholars, using bigger sample sizes, to consider the discussion on lag time when examining cross-lagged reciprocal effects.

8. See Appendix A for the full set of commands used to estimate Model 3. 